\title{
Human 2.0: Homo-Petroleosus Becomes Homo-Solarus
}

\author{
Saul Griffith, \\ Otherlab, San Francisco, CA, USA
}

\begin{abstract}
Upon receipt of the brief for this article I was tempted to reject it wholesale, for in some respects it was an invitation to play God, or eugenecist, for humanity. On second thought, I realized it was a wonderful opportunity to use an engineer's, or a designer's method, to contemplate the future of humanity, at the individual and societal level, and to contemplate reaching that future through design rather than evolution. As a thought experiment it allows us to reflect upon our existence, and how we might improve it through our own intervention.
\end{abstract}

Without thinking about the problem for too long, however, I was struck by one overwhelming challenge to this task. As designers we have become quite good at designing simple objects, like knives and forks, chairs and tables, or bicycles, but we are still not very good at designing complex systems. In simple mechanisms it is very easy to imagine and then make the mechanism perform some simple behavior that you would like, reliably and robustly. In complex systems, like a long computer program for example, or the human biological system, or the electricity grid, or earth's ecosystem, it is easy to upset the balance with a very small change that has drastic unintended consequences.

It was tempting to write a laundry list of the things I'd like to be able to do, such as fly, breathe underwater, run faster, be stronger, link my brain to the web, have better memory, live longer and be immune to diseases, all of which I can imagine there are ways to augment human capacity to do, but for me right now it is a more interesting task to contemplate the way we design ourselves in the context of one of humanity's greatest challenges. The defining issue for the next century is going to be how humanity deals with the realization that the resources of our planet are finite, and that our collective actions at a small scale are having large-scale, detrimental effects on the environment. Consequently, we are diminishing our capacity to live well within that environment. Very realistically, this challenge is about our capacity to continue to live high-quality lives in a world and environment we will enjoy.

So why do I raise the issue of complex systems, when I contemplate re-designing myself (and humanity) to deal with our environmental footprint? Because we all have to acknowledge, deeply, fundamentally, that we are part of a collective, each of us an ant in the enormous ant farm called humanity, and that all of our actions are reducing our capacity to live well in the ant farm. So not only do I have to redesign myself here, but redesign the species. The design task written succinctly might be "redesign humans to be the first species to ever consciously accept their role in a larger, finite ecosystem, and to design themselves and their collective lifestyle to sustain their species at a quality of life of their choosing". Written colloquially it might be "redesign homo-petroleosus (oilyman) to become homo-solarus (solar-man)".

We have until 2025 to profoundly change the way we produce and use energy. We could hope that a confused array of carbon taxes, voluntary individual actions, hoped-for technological advances, or beneficent aliens saves us from some climate and environmental catastrophe, or, we could look at the challenge as an engineer would. Engineers use reductionist logic to make complex design problems manageable, so I'll begin with that reductionist logic to create the background for our redesign. (Amidst the reductionist logic I will insert crazy ideas in brackets - that's the designer thinking out loud about the problems the engineer identifies.)

Step 1: Using our capacious evolved brain power, understand the links between our emissions (principally $\mathrm{CO}_{2}$ ) and the temperature of our planet lor ant farm, or Petri dish, or spacecraft ...)

It can be argued that maximally we can afford a $\mathrm{CO} 2$ concentration of 450 parts per million, though 400 or 350 might be an even safer bet to ensure maximum quality of life and undisturbed progress towards homo-solarus.

[*Maybe we should become photosynthetic based so that we convert $\mathrm{CO} 2$ to oxygen instead of the other way round?]

Step 2: From a target CO2 concentration of 400 parts per million, we can infer what amount of carbonaceous (principally fossil fuels) we can burn.

Given that the oceans absorb around 2 billion tonnes of carbon each year, we can infer as a rough estimate that we can burn 2 billion tonnes of fossil fuels each year. 2 billion tonnes of carbon is around 7 billion tonnes of $\mathrm{CO} 2$, which works out at around 1 tonne of $\mathrm{CO} 2$ per person, per year.

[*Maybe given that flying and driving and living in houses are three of our most carbon-intense activities, we should reconsider living in trees, and swinging from branch to branch?]

Step 3: Estimate how much energy humanity can derive from that fossil fuel. 

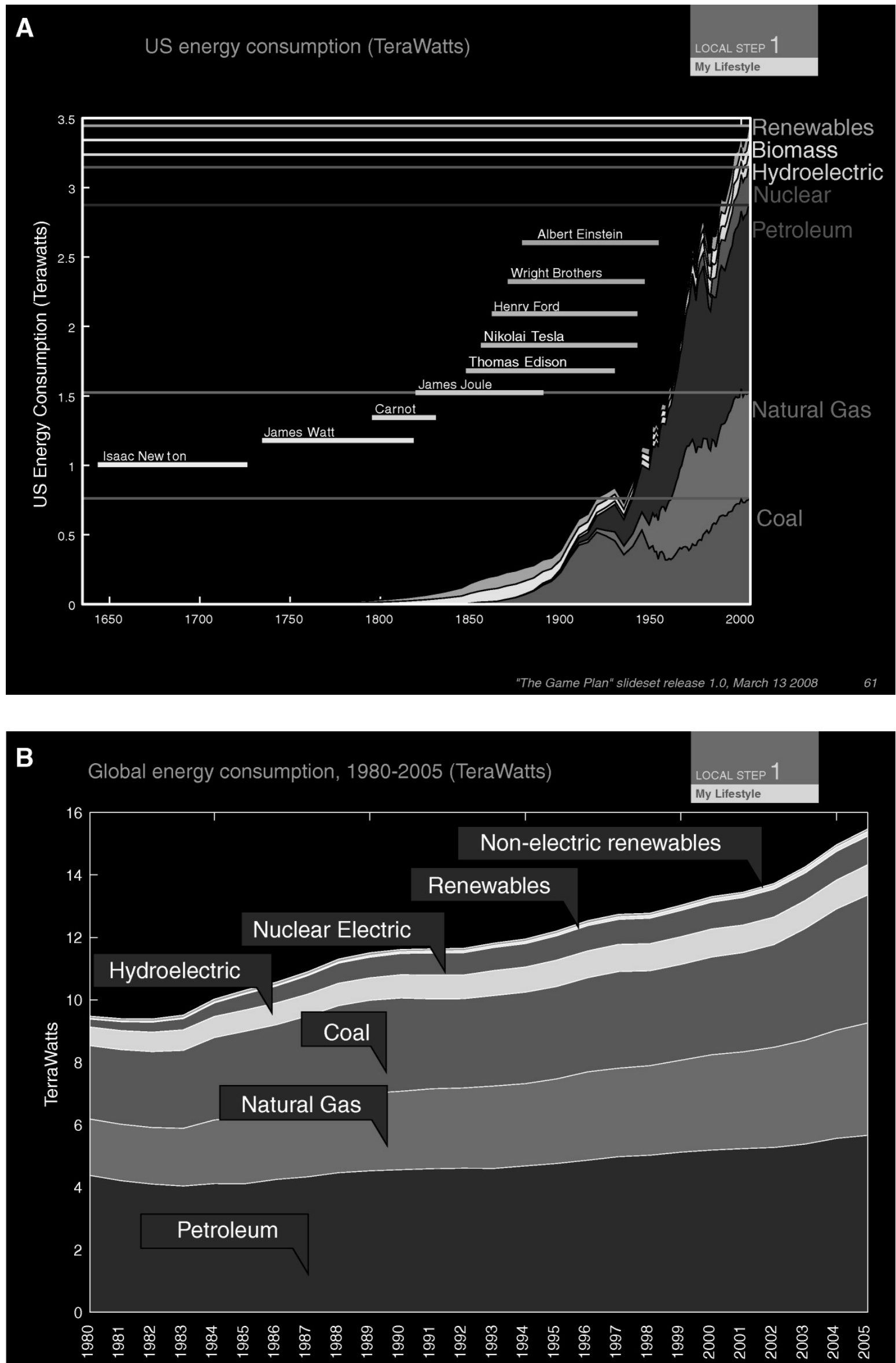

Figure 1 
Given the existing mix of oil, coal, and natural gas that we use for our primary power production, we can probably obtain around 2-3 TeraWatts (TW) (or 2-3000 000000 000 Watts) of power from fossil fuels.

Step 4: Determine how much power we use now, and therefore how much new clean power we need.

Given that we consume 15 TeraWatts of power now, and that roughly 1.5 TW comes from non-carbon sources (mostly nuclear and hydroelectric, a little from solar and wind) this means we need to create $15-1.5-2.5=11$ TeraWatts of non-carbon emitting power.

[*It looks like one of the principal design goals is going to be figuring out how to design humans and societies who use less power while maintaining a high standard of living.]

\section{Step 5: How much power is that for each of us?}

There are around 6.65 billion people at the time of writing this article. If we distributed the 15 TW of power humanity currently uses equally amongst all of those humans, we would get 2255 Watts each. If we distributed only the 3 TW from fossil fuels, we'd get only 450 Watts each. For perspective, the average American uses more than
11000 Watts; the average northern European: 7000 or 8000; the average southern European 5000; the average Chinese citizen 2000 Watts.

[ ${ }^{*} A$ terrible conclusion here might be to reduce the population - that's not a very palatable idea, and as we've seen with wealthy nations, birth-rates typically plateau and fall off to barely a level of replacement, so perhaps more palatable is designing humans so they are all part of wealthy nations, and they all use far less energy, or produce truly prodigious amounts of renewable energy.]

Now let's look at the design challenge again. How do we re-design Human 2.0 such that we are homo-solarus, the first species to consciously acknowledge that we live in an ecosystem of finite resources and that we must manage that ecosystem and our impact upon it if we wish to continue to live well within it?

The very first thing we need to do is design that understanding into all future humans. From birth we must receive the knowledge that nothing is infinite, everything we do has a consequence, and that we are managing our role in the environment we are part of such as to sustain the human endeavor as long as possible. We could of course choose to kill off the majority of us in an orgiastic

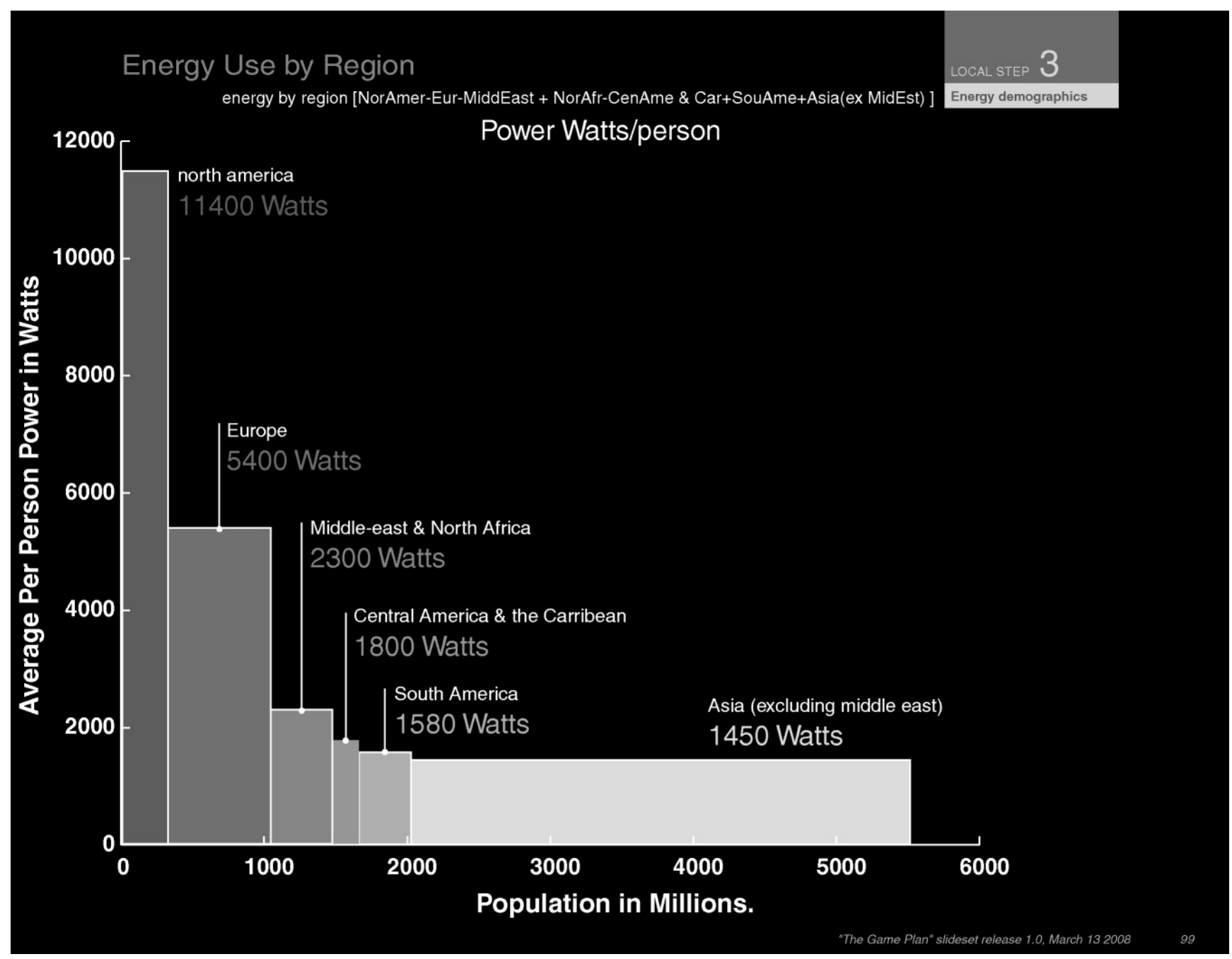

Figure 2 
final dance party fueled by oil and coal, but that's what we are trying to avoid with this re-design.

To put the numbers we reached above into perspective, I calculated the power consumption of my own life. As I sit here writing this article, my body is consuming $60-80$ watts of power. That's the equivalent of $60-80$ joules per second. It's also roughly equivalent to the power consumed by an incandescent light bulb. The energy for that power is provided to me in the form of food.

That is not the only power I consume. There is the power that I consume due to my lifestyle. I used to think I was environmentally conscious, and an exemplar of homosolarus, but these calculations have illustrated that I am indeed one of the principal offenders and very much homo-petroleosus. Of the approximately 14437 Watts of power I used continuously over 2007, it was proportioned in the following way:

Flying: 7992 Watts $-55 \%$
Driving: 1491 Watts - 10\%
Bicycle \& public transport: 108 Watts - 1\%
Society: 400 Watts - 3\%
Work Electric: 411 Watts - 3\%
Work Heat: 201 Watts - 1\%
Home Electric: 135 Watts - 1\%
Home Heat: 597 Watts - $4 \%$
Food: 772 Watts - $5 \%$
Consumer items: 2311 Watts - $16 \%$

What are the possible design changes that could change this?

We consume a lot of power keeping ourselves warm. A simple solution would be to insulate ourselves more effectively. Hair, it turns out, is highly effective for this. One of my first hacks for homo-solarus is a fine layer of silky hair, everywhere. We would probably also need to change our sense of fashion, which is going to be a cultural fix, not a technical one. Thermodynamically speaking, people who live in cold environments should be shorter, rounder, fatter, with more insulation in body fat, and proportionally less surface area by which to lose heat through radiation. Given that I'm encouraged to only use re-designs that I'm prepared to embody myself, I'm going to choose hairiness over roundness. People who live in very warm places should be taller and thinner and have more active sweat glands to dissipate excess heat and to be more effectively cooled by light breezes. We should probably have much larger ears, like elephants, whereby we can pump blood to be cooled as we wave or flap our ears. I would probably engineer out my cold sensitivity so that I do not require hot showers; cold showers should feel at least as pleasant as a long shower. Given that providing water to me is energy intensive for a host of reasons beyond heating it, I would also like to consume less of it. The overwhelming majority of water is not used for drinking, but in washing, bathing, and other activities. I could drastically reduce my need for bathing by genetically modifying my sweat glands to produce more pleasant-smelling sweat.
We will be exposed to increased UV radiation. This would also be solved through a light hair covering, and increased skin pigmentation will undoubtedly help. Rather like a polar bear, the optimal human might be dark skinned with light-colored hair covering all of the body. Through these changes alone I can probably reduce $5-10 \%$ of my power consumption. For people in places colder than San Francisco, the savings will be even greater.

We use a huge amount of power to light our lives artificially. We could lower our power consumption and hence $\mathrm{CO} 2$ production significantly by using daylight hours more effectively. Many people don't like waking early because the mornings are cooler. Were we hairy, this might be less of a problem, though what could be the biggest boon is improving the sensitivity of our eyes, hearing, and smell, such that we didn't require so much artificial light. I would need less artificial light for reading and socializing, and fewer street lights, and fewer car lights. It might be advantageous to have ultrasonic hearing, like a bat, so that I can do navigation by echolocation, and hence I' $d$ be able to travel without fear of collision in complete darkness. I can imagine genetic modifications to my eyes to give them more light sensitivity; there are many creatures in nature who already have such eyesight. I would also accept slim, high-resolution night-vision glasses, but they'd have to be at least as fashionable as normal eyeglasses for me to adopt them. I think that, in general, I will choose external technological fixes over genetic modification. The ultrasonic sense will be tremendously difficult to engineer genetically, so I suspect I will need to add that via an electronics-brain interface - more on that later. Reducing my need for lighting by $90 \%$ should reduce my power consumption by a further $2-4 \%$.

I'm currently an omnivore who eats meat regularly. That meat consumption is probably responsible for around $50 \%$ of my power consumption. Eating foods from faraway places also increases the power requirements of my food intake. I'd like to engineer myself to desire meat less often than I do at the moment. Perhaps this is done through more effectively extracting energy from food, though evolution has already made us quite effective at that. I can achieve some of this goal through the social technologies otherwise known as religions. If I choose to become religious about vegetarianism and eating locally produced foods I can probably reduce my power consumption by another $2-3 \%$. In reality, I probably don't even need religion for this as I already know that I would be a lot healthier than I already am if I was at least mostly a vegetarian, and I ate fresh food produced near to where I live. One thing I should probably do is change my palate to crave fewer sugars. Sugars are high in energy to produce, and increase diabetes rates. I would like to engineer out the desire for sweets and perhaps engineer in an insatiable desire for mushrooms, potatoes, and brussels sprouts. Interestingly I could look at building in much higher disease tolerance so that I didn't require my food to be as fresh, or my water as clean, and still remain healthy as I ate it. I know it doesn't sound appetizing, but it would drastically lower my power consumption.

War-mongering is an enormous consumer of resources. It is difficult to estimate, but if we were all pacifists and 


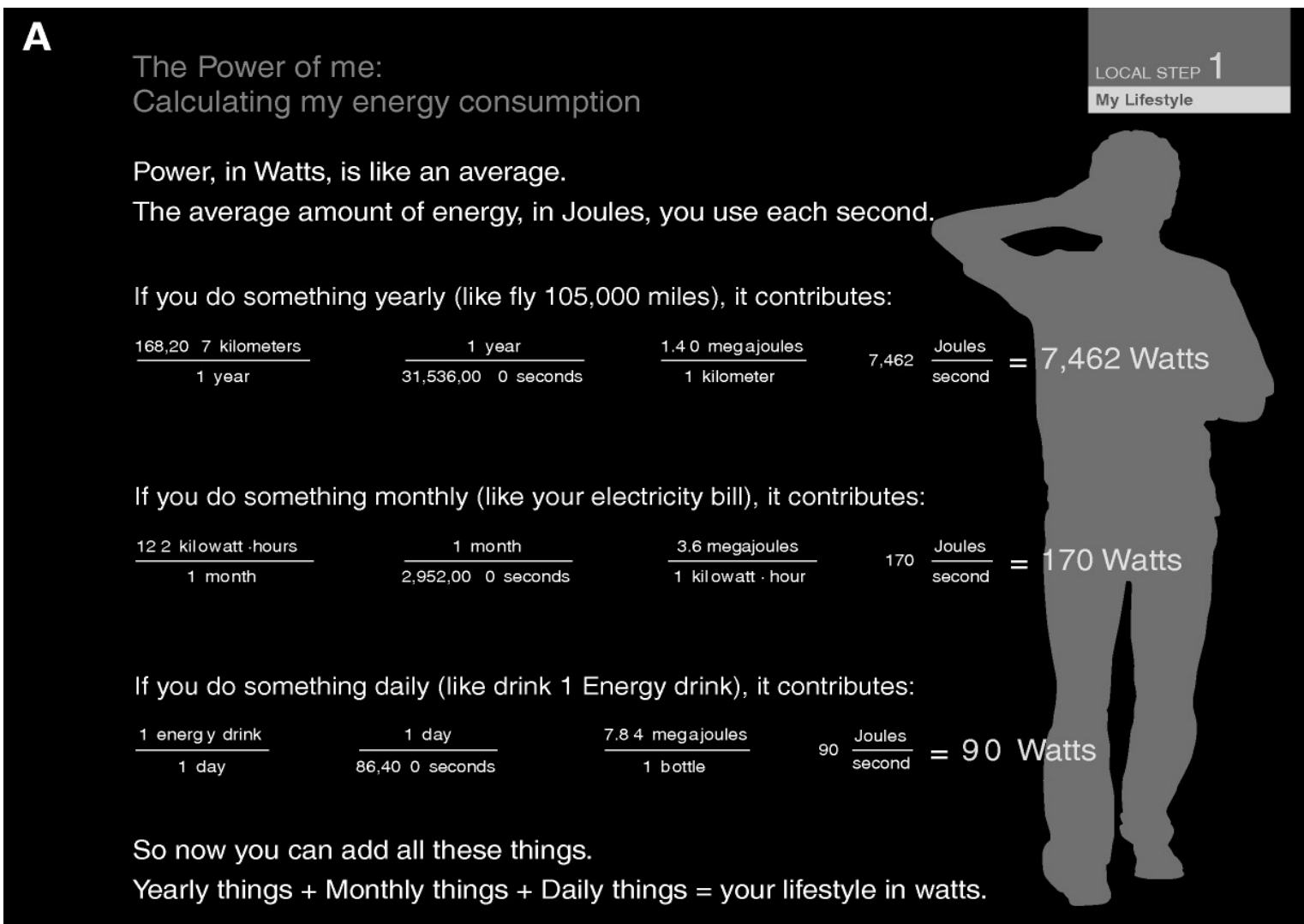

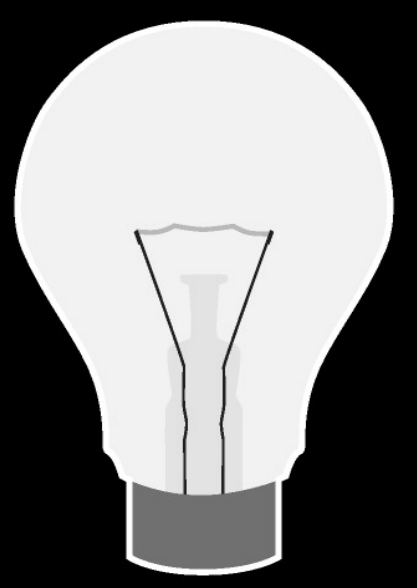

Think of your life in light bulbs....

A 12,000 Watt lifestyle is $120 \times 100$ watt light bulbs burning permanently.

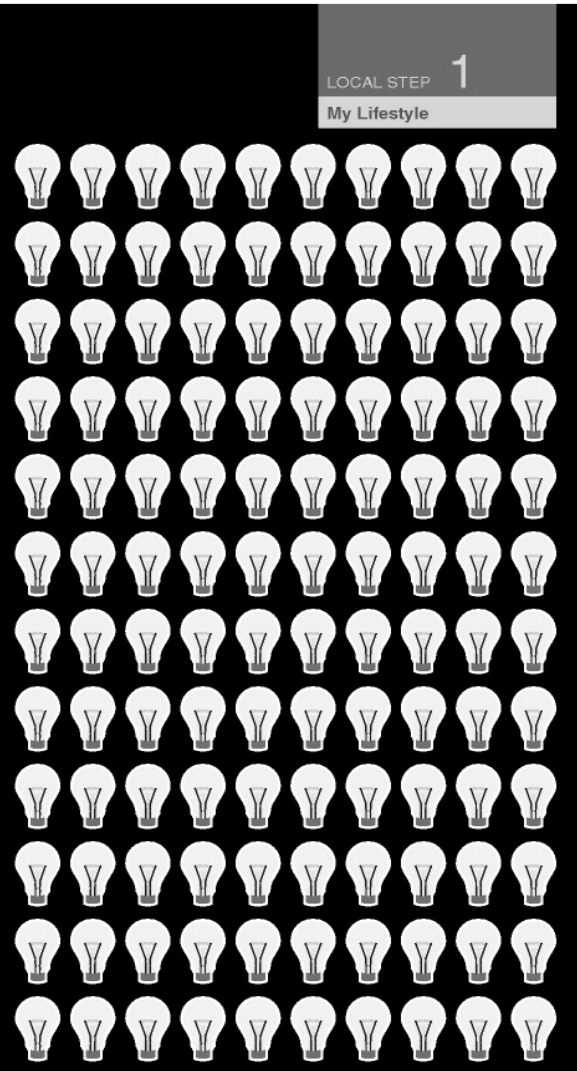

Figure 3 

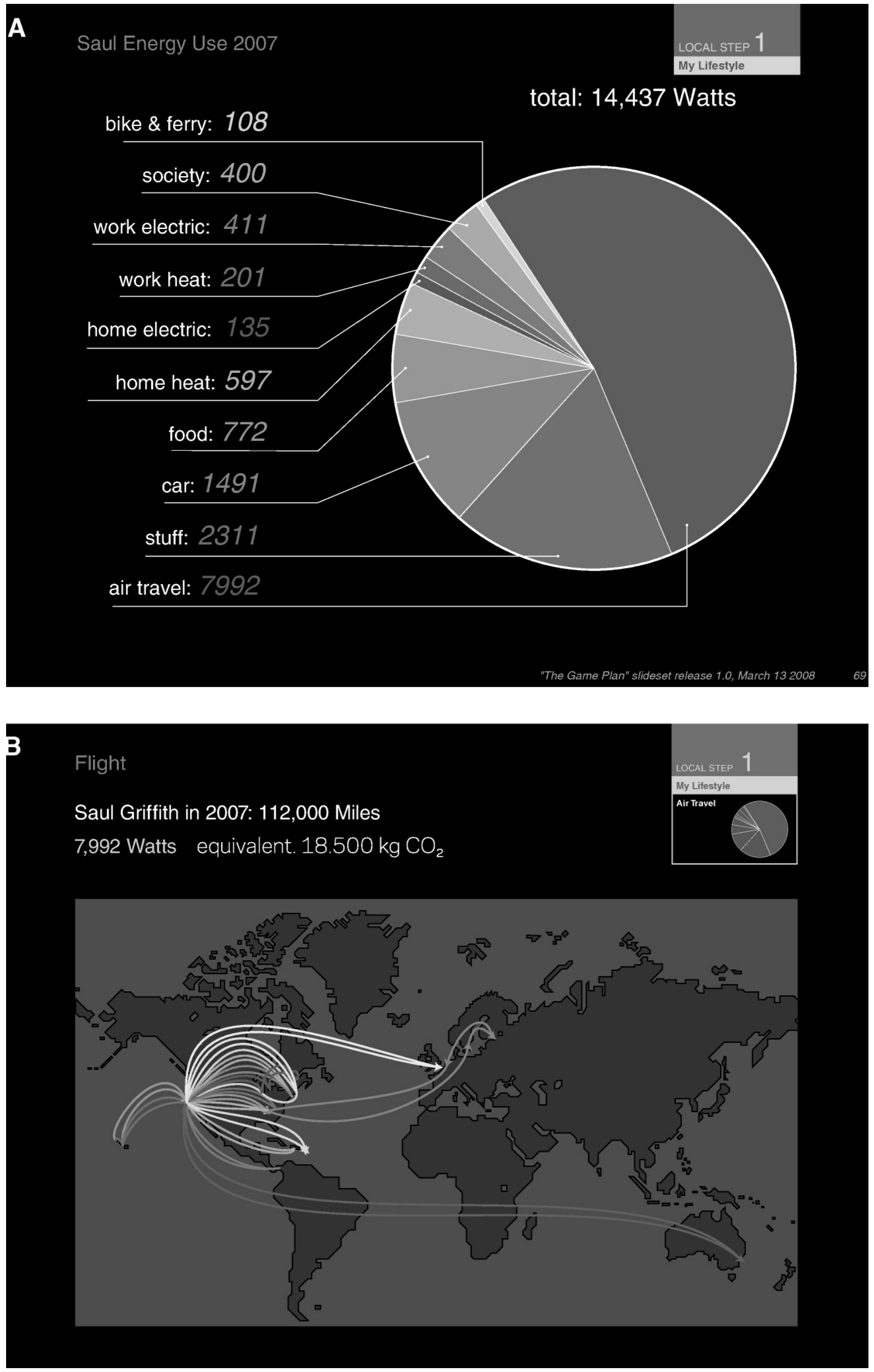

Figure 4 
war didn't exist we would at least save the power consumed by the military (not to mention the power saved by not having to rebuild war zones). I will hazard a guess that this could be a $2-5 \%$ saving in my power consumption if it were applied to everyone, everywhere. There are two or three options by which we might achieve this. The first would be compulsorily administered drugs to help us overcome our violent urges, something like the SOMA in Brave New World. Oxytocin, sometimes colloquially known as the "pair-bonding drug", might be the SOMA we need. It is produced in high doses during child-birth and breast-feeding, and is even emitted by infants - some believe as a defense mechanism against infanticide. We could also look to genetics. Chimpanzees, who are one of our closest relatives, are famously violent towards each other. Bonobo monkeys on the other hand, which are only slightly further away from us genetically, are notoriously loving animals. We could identify the genetic origins of the Bonobo's pacifism (and famous sexual liberalism) and engineer that into ourselves.

Obviously much of our power consumption comes from transport. In fact, in my life, it looks like more than $60 \%$ of my power consumption comes from flying and driving. I doubt that we can improve car and plane efficiencies enough (it would need to be more than a factor of 10) for me to travel as much as I do and still survive on a 2255 Watt diet. What human adaptations might allow us to travel less? Telepathy would be high on the list: the capacity to communicate with extraordinary clarity without having to travel to a physical location with the other parties involved. The lesser versions of telepathy, the mobile phone, internet, and video-conferencing, have not yet conclusively led to less travel, but perhaps there is a technological fix there that will help. I suspect if I had a sufficiently high bandwidth connection directly to my brain that could control a telepresence robot elsewhere in the world, I would not need to fly to remote locations nearly as often as I do now. The power consumed to transport anything increases with the increase in speed of transport, as well as with the aerodynamics of the object doing the transporting. One solution is to travel much slower; a bicyclist is about the optimum. Perhaps my peaceful Bonobo modifications would also confer upon me a satisfaction to travel at much less rapid speeds. Or, by increasing my lung capacity and muscle type and muscle distribution, I would be able to run or bicycle much longer distances with less discomfort. With increased communication capacities, I wouldn't need to be moving fast as I could work as I travelled slowly and peacefully, sailing to Europe on the power of the wind while performing my work remotely by computer or mind-control, or doing half of my day's work while riding my bicycle casually on the commute.

My consumer behavior is another major contributor to my power consumption. By travelling less, I wouldn't need to own a car, and perhaps with sufficient insulation from my new body hair, my house wouldn't need to be as heavily built and insulated. With an increased immune system, I wouldn't need so many cleaning products and washer/dryer cycles for my clothes and food dishes. UItimately, though, I need to reduce my consumer product consumption tenfold. Probably the greatest change there is cultural, or perhaps ego-related. As a man, it is easy for me to say that we would only have to genetically and socially engineer women to choose men not for their display items (might we not see sports-cars and yachts as sexual display?), but rather for their empathy to nature and the world. I guess, turning that thinking around, I should also engineer myself not to choose female partners for their clothes, make-up, and perfumery, but for their silky pelts, earthiness, and natural scent.

Of all of the ideas for Human 2.0 that I have mentioned above, the ones that are most appealing to me are increased light sensitivity with my vision, and the braincomputer interface. Not only can I imagine the braincomputer interface helping me prevent unnecessary travel, but I could imagine using it to control any robotic or computer-controlled machinery. Quite aside from wanting to solve the human energy problem, this would be an amazing modification for humans.

It is clear that we have an incredible challenge ahead for humanity. Probably easier than re-engineering ourselves, or drastically reducing our population by intolerable means, is a profound technological focus on clean technologies and renewable energies. My 14400 Watts of power could realistically by produced by a set of highefficiency solar panels of $144 \mathrm{~m} 2$. That's a square $12 \mathrm{~m}$ by $12 \mathrm{~m}$, or $35 \times 35$ feet. It's a wind turbine of $4 \mathrm{~m}$ diameter. I should install that myself this year, as should everyone with the means to do so. I should also use efficiency measures everywhere that I can to reduce my power demand. These are changes more likely to be brought about by peer pressure rather than brain chips, but I was struck as I wrote this article how many of these problems were more amenable to social engineering than technology design. I suspect that tells us a lot about the current situation with climate change. We need to change our minds more than we need to change anything else.

\section{CORRESPONDENCE}

Saul Griffith, Otherlab, 2800 Third Street, San Francisco, CA 94110 , USA.

E-mail: saul@zeroprestige.org

Published online 18 November, 2009

ISSN 1749-3463 print/ ISSN 1749-3471

(C) 2008 Artifact

Copyright to illustrations in this article resides with the creator unless otherwise noted. Artifact publishes illustrations in accordance with commonly acknowledged fair use of visual materials for non-commercial research purposes. Creators who feel that publication is in violation of copyright or fair use should contact the editors. 